\title{
Vascular Dysfunction in Brain Hemorrhage: Translational Pathways to Developing New Treatments from Old Targets
}

\section{Paul A. Lapchak ${ }^{1 *}$ and Qiang $\mathbf{W u}^{2}$}

${ }^{1}$ Director of Translational Research, Cedars-Sinai Medical Center, Department of Neurology, Davis Research Building, D-2091, 110 N, George Burns Road, Los Angeles, CA 90048 USA

${ }^{2}$ Project Scientist, Cedars-Sinai Medical Center, Department of Neurology, Davis Research Building, D-2094E, 110 N. George Burns Road, Los Angeles, CA 90048 USA

\begin{abstract}
Hemorrhagic stroke which is a form of stroke that affects $20 \%$ of all stroke patients is a devastating condition for which new treatments must be developed. Current treatment methods are quite insufficient to reduce long term morbidity and high mortality rate, up to $50 \%$, associated with bleeding into critical brain structures, into ventricular spaces and within the subarachnoid space. During the last 10-15 years, significant advances in the understanding of important mechanisms that contribute to cell death and clinical deficits have been made. The most important observations revolve around a key set of basic mechanisms that are altered in brain bleeding models, a hemorrhage cascade, including activation of membrane metalloproteinases, oxidative stress and both inflammatory and coagulation pathways. Moreover, it is now becoming apparent that brain hemorrhage can activate the ischemic cascade in neurons, glial cells and the vascular compartment. The activation of multiple pathways allows for the opportunity to intervene pharmacologically using monotherapy or combination therapy. Ultimately, combination therapy or pleiotropic compounds with multi-target activities should prove to be more efficacious than any single therapy alone. This article provides a comprehensive look at possible targets for small molecule intervention as well as some new approaches that result in metabolic down-regulation or inhibition of multiple pathways simultaneously.
\end{abstract}

Keywords: Antioxidant; Matrix membrane metalloproteinase; Factor VIIa; Hemostasis; Subarachnoid hemorrhage; Normobaric oxygen; Hyperbaric oxygen; Hypothermia; Hydrogen gas

\section{Brain Hemorrhage: Incidence and Pathophysiology}

Brain hemorrhage stroke occurs in approximately $20 \%$ of all patients with a stroke [1-3]. There are two main categories of hemorrhagic stroke, intracranial hemorrhage including epidural hematoma, subdural hematoma and subarachnoid hemorrhage (SAH), and intracerebral hemorrhage ( $\mathrm{ICH})$ including intraparenchymal hemorrhage (IPH) and intraventricular hemorrhage (IVH). The terms ICH and hemorrhagic stroke are often used interchangeably, but they can be distinguished from hemorrhagic transformations normally associated with ischemic stroke.

ICH is associated with a rapid and higher mortality rate than ischemic stroke and substantial brain damage occurs through multiple mechanisms. The 30 -day mortality rate for ischemic stroke is $8-12 \%$, whereas hemorrhagic stroke is estimated to be around 50\% [4-7]. Moreover, despite presenting with similar focal neurologic deficits, patients with hemorrhagic stroke tend to be more severe than patients with ischemic stroke and less than $20 \%$ of hemorrhagic stroke patients regain functional independence. There are still no specific treatments for most types of $\mathrm{ICH}[7,8]$. Patients with $\mathrm{ICH}$ may require neurosurgical evaluation to detect and repair the source of bleeding, and remove the clot to prevent expansion and secondary repercussions such as ischemic damage.

There are many causes for ICH, which generally occurs in small arteries or arterioles and is commonly due to hypertension, intracranial vascular malformations or cerebral amyloid angiopathy [9]. The pathophysiology of ICH is triggered by bleeding directly into the brain parenchyma, often as a result of leakage from small intracerebral arteries that have been compromised. Vascular damage due to cerebral amyloidosis primarily affects the elderly and represents up to $10 \%$ of hemorrhagic strokes. In addition, commonly used therapeutics such as anticoagulants, platelet inhibitors $[10,11]$ and thrombolytics (tissue plasminogen activator; tPA, Alteplase $^{\mathrm{TM}}$ ) typically used to treat acute myocardial infarction (AMI) or acute ischemic stroke (AIS), in particular, can lead to iatrogenic hemorrhagic stroke and a prior history of stroke, per se, also represents an important risk factor for ICH [12].

\section{Preclinical Models and Translational Studies}

An extensive amount of funding has been dedicated to preclinical research studies to identify mechanisms involved in ICH and to subsequently test strategies in animal models, not only for ICH reduction, but also for clinical improvement. Three of the most commonly used animal models are briefly reviewed here: collagenase injection model, whole-blood model and embolization-induced hemorrhage. There is significant scientific value in using a combination of 2 or more of the models to develop mechanism-based treatments strategies to be applied to stroke patients.

The collagenase model has been used by many leading hemorrhage groups including Lyden and colleagues [13-15] and Rosenberg et al. [16-18]. Briefly, the injection of the membrane protease, collagenase into the striatum results in dissolution of the membrane matrix that supports cells resulting in the formation of a hematoma. It appears that Type IV collagen in the basal lamina is the substrate for the bacterial collagenase used in most studies [19,20]. This model has been used by

*Corresponding author: Paul A. Lapchak, Ph.D, FAHA, Director of Translational Research, Cedars-Sinai Medical Center, Department of Neurology, Davis Research Building, D- 2091, 110 N, George Burns Road, Los Angeles, CA 90048 USA, Tel: 310-248-8188; Fax: 310-248-7568; E-mail: Paul. Lapchak@cshs.org

Received June 28, 2011; Accepted July 07, 2011; Published September 20, 2011

Citation: Lapchak PA, Wu Q (2011) Vascular Dysfunction in Brain Hemorrhage: Translational Pathways to Developing New Treatments from Old Targets. J Neuro Neurophysiol S1. doi:10.4172/2155-9562.S1-e001

Copyright: (c) 2011 Lapchak PA, et al. This is an open-access article distributed under the terms of the Creative Commons Attribution License, which permits unrestricted use, distribution, and reproduction in any medium, provided the original author and source are credited. 
many research laboratories as a model of ICH or SAH [13-16,18,19,2126]. Many investigators target cortical substructures such as the caudate putamen in this model and doing so allows for a behavioral function measures due to a lesion in the nigrostriatal pathway. A lesion in the pathway produces neuronal degeneration and behavioral asymmetry that can be detected in rodents as rotational behavior. The advantages allow investigator to study treatments that can limit the collagenaseinduced bleeding response and hematoma expansion. The model is particularly relevant to the clinical condition because continued bleeding occurs in 14-20\% of all ICH patients and lasts for over $6 \mathrm{~h}$ in $17 \%$ of cases $[27,28]$. However, the drawbacks are that there is no underlying vascular pathology, and bleeding results from the rupture of many vessels, whereas rupture of a small, deep-penetrating artery in humans.

In the whole-blood or blood product injection model, an animal's own blood (autologous) or donor blood (non-autologous) is injected directly into the brain tissues [13-16,18,21-24,29-37], also using the caudate putamen in many cases. Zhang and colleagues have successfully used the model to identify target mechanisms for treatment [38-41]. The advantage of the whole-blood model is that only blood is introduced into the model system. The drawbacks are the lack of underlying vascular pathology and vessel rupture, which is normally seen in the human stroke population.

An embolism-based model has also been used to study interventions that can reduce $\mathrm{ICH}$. The rabbit large clot embolism model (RLCEM) has been used extensively to decipher mechanisms involved in hemorrhage and for the preclinical development of pharmacological strategies that may reduce embolism- and tPA-induced hemorrhage [5,42-47]. The favorable characteristics of the RLCEM include the study of 3 types of ICH: hemorrhagic infarction, petechial hemorrhage and parenchymal hemorrhage ( $\mathrm{PH})$ [45] regardless of whether or not thrombolytics are administered. The symptomatic $\mathrm{PH}$ defined as large collections of blood in the parenchyma without intervention into brain tissue, originally is thought to occur consequent to reperfusion into a devitalized artery [48]. In the model, no specific structure can be targeted because the clot is injected through an indwelling carotid catheter and becomes lodged in one or more vessels in brain, depending on whether the clot remain intact or fragments. Most often, the result is blockage of the middle cerebral artery (MCA), which causes a large reduction of cerebral blood flow to one brain hemisphere. In essence, the RLCEM in an embolic stroke model with a significant hemorrhage component. This model has been used by many research laboratories as a model of ICH and tPA-induced ICH [44-47,49,50].

\section{Inflammatory Reactions and Vascular Damage}

\section{Coagulation factors}

As a consequence of brain hemorrhage, enzymes involved in blood clotting and clot lysis are produced [47,51-53]; however, many of them have potential toxicities. Primary hemostasis is initiated when vascular injury triggers adherence of platelets to proteins within in the vascular endothelium using glycoprotein (GP) Ia/IIa receptors. This is followed by platelet aggregation by means of docking proteins or sites to form the primary hemostatic clot. The sequence of platelet aggregation is mediated by von Willebrand factor, which forms links between the platelet GP Ib/IX/V and collagen [54-56]. Once they bind and are thereby activated, platelets undergo structural and conformational changes and begin platelet-platelet aggregation via the GP IIb/IIIa receptors. Secondary hemostasis, which is comprised of two specific pathways, the "intrinsic" or "contact activation" pathway and the "extrinsic" or "tissue factor" pathway, results in local activation of plasma coagulation factors and the generation of a fibrin clot that reinforces the platelet aggregate. The classical model of blood coagulation involves a complex "cascade" of zymogen activation reactions involving coagulation factors, 6 in the intrinsic pathway (factors VIII, IX, XI, XII, prekallikrein, and high-molecular weight kininogen), 1 in the extrinsic pathway (factor VII), and 4 in a common pathway (factors II, V, X, and fibrinogen). The main role of the extrinsic pathway is to generate thrombin to convert soluble fibrinogen into insoluble strands of fibrin which is the backbone of a clot. Following damage to the blood vessel, Endothelium Tissue Factor (ETF) is released, forming a complex with Factor VIIa, which then activates Factor IX and X. Factor VII is a coagulation factor in the extrinsic coagulation pathway and is part of a series of hemostatic defense mechanisms [55,56]. Factor VII itself can also be activated by thrombin leading to a cyclic complex including the activation of prothrombin to thrombin. Factor VIIa is present in excess of any other activated coagulation factor could be a potential target for ICH therapy. However, clinical results in hemorrhage trials with Novoseven have been quite disappointing [57], primarily because there was an increased incidence of thromboembolism causing ischemic damage and clinical deficits.

\section{Thrombin}

Thrombin is an essential component of the coagulation cascade and it is produced in the brain immediately after ICH. Recent research has suggested that thrombin is a pleiotropic molecule that causes vascular damage, an inflammatory response, oxidative stress, and also has direct cellular toxicity, which is mediated in part by protease activated receptors (PARs) [58-60]. Some studies have noted that thrombin at high concentrations can activate potentially harmful pathways [51, $61,62]$. Direct infusion of large doses of thrombin into the brains causes inflammatory-cell infiltration and brain edema formation partly due to the direct opening of the blood brain barrier (BBB). A recent key study [63] showed that thrombin mediates endothelial permeability and the introduction of thrombin in brain causes vascular damage, a result that can be blocked by the small molecule direct thrombin antagonist argatroban. Moreover, thrombin stimulates PARs expressed on microglia/macrophages to activate these cells via recruitment of mitogen-activated protein kinases (MAPKs), and produces several inflammatory mediators, which contribute to edema formation through disruption of the BBB [61]. Similarly, another recent study has suggested that thrombin induced edema is mediated by stimulating PARs to activate src family kinases, which are a family of protooncogene tyrosine kinases [64]. Src family kinase members mediate BBB permeability changes and brain edema by phosphorylating membrane metalloproteinases (MMP's), tight junction proteins and other BBBrelated proteins [65]. Thus, these kinases may be appropriate targets for further development to attenuate the downstream detrimental effects of thrombin.

\section{Cytokines}

The major inflammatory cells that are activated and accumulate within the brain after ICH are blood-derived leukocytes, macrophages, and resident microglia [66,67]. Microglia are believed to be the first non-neuronal cells to react following CNS injury. After brain injury, microglia are activated to undergo morphologic including upregulation of pro-inflammatory cytokines, migration, proliferation and phagocytic behavior [68]. Microglia, "brain macrophage", which when activated release a variety of cytokines [69-71], reactive oxygen species (ROS) [72-74], and other potentially toxic factors, suggesting that activated microglia/macrophages might contribute to hemorrhage-induced 
early brain injury [26,75]. Infiltrating leukocytes are also believed to play a role in ICH-induced brain injury. Neutrophils are the earliest leukocyte subtype to infiltrate into the hemorrhagic brain, and these may damage brain tissue directly also by producing ROS, releasing proinflammatory proteases [76], and modulating BBB permeability [77]. Substantial evidences have suggested that leukocytes/macrophages and activated microglia are major CNS sources of cytokines, chemokines, prostaglandins, proteases, and other immunoactive molecules after ICH $[66,78-81]$.

Many investigators have studied cytokine changes after ICH and have shown that two primary molecules, TNF- $\alpha$ and IL- $1 \beta$ are elevated in various experimental models of brain injury. TNF- $\alpha$ is a pleiotropic cytokine that received a lot of attention because it has multiple biologic activities that are temporally organized including the stimulation of acute phase protein secretion, vascular permeability and post-ICH brain edema formation $[82,83]$. TNF- $\alpha$ expression is increased in response to $\mathrm{ICH}$ when presented with either autologous blood or thrombin $[83,84,85]$. TNF- $\alpha$ also mediates hemorrhage in brain following embolic strokes [86]. TNF- $\alpha$ and its family of receptors represent possible interventional targets to reduce hemorrhage damage or hemorrhage-induced ischemic damage $[87,88]$. Like TNF- $\alpha$, there is a persistent increase in IL- $1 \beta$ observed in brain following autologous blood injection $[80,89]$. Similarly, expression of the TNF- $\alpha$ receptor and IL- $1 \beta$ were both upregulated following intrastriatal blood infusion [90]. TNF- $\alpha$ and its family of receptors and IL- $1 \beta$ represent possible interventional targets to reduce hemorrhage damage or hemorrhageinduced ischemic damage $[87,88]$.

\section{Free radicals and vascular damage}

Free radicals have been a focal point in the development of treatments for stroke. They are reactive molecules that have one or more unpaired electrons. These reactive species often are divided into two groups, ROS and reactive nitrogen species (RNS). ROS usually refers to superoxide, hydrogen peroxide $\left(\mathrm{H}_{2} \mathrm{O}_{2}\right)$, hydroxyl radical, singlet oxygen, whereas an RNS can include nitric oxide (NO) and peroxynitrite. Free radicals and their related non-free radical reactive species have been implicated in stroke pathophysiology as an important contributor to cell and tissue injury [91-93]. Increased levels of free radicals can cause damage to virtually all cellular components, including DNA, lipids, and proteins, which then leads to injury of neurons, glial cells, blood vessels and the vasculature. Free radicals can exert effects directly on cells and also interact with various cellular molecular pathways which contributes to the development of brain edema and cell death [66].

ICH is also associated with robust induction of heme oxygenase (HO) in microglia/macrophages, and the enzyme catalyzes degradation of heme into iron, carbon monoxide (CO), and biliverdin, which is then converted to bilirubin by biliverdin reductase [94]. ICH causes iron accumulation in the brain and non-heme iron has been shown to increase threefold after ICH in rats [95]. Furthermore, intracerebral infusion of iron causes brain injury and deferoxamine reduces ICHinduced brain damage, suggesting that iron plays an important part in brain injury after ICH [96-98]. Iron and other products contribute to pathological changes such as increase in oxidative stress, formation of edema, infiltration of neutrophils, and induction of neuron death [61]. Moreover, Iron and iron-related products catalyze hydroxyl radical production and lipid peroxidation $[99,100]$, which expose the brain cells to increased levels of oxidative stress. The production of ROS is an inevitable consequence of normal oxidative metabolism, but high ROS levels can be lethal [101-103] and must be regulated because they are involved in a series of processes such as contributing to brain edema by triggering the induction and activation of MMP family members both directly and indirectly [92]. The direct process may involve the oxidation or nitrosylation of MMP, resulting in MMP activation [104]. The indirect process may involve redox-sensitive elements of transcription factors such as nuclear factor kappa-light-chain enhancer of activated B cells (NF- $\mathrm{KB}$ ) and activator protein 1 (AP-1), which is known to be an integral part of the binding sites for MMP transcription $[105,106]$. Excessive hydrogen peroxide production has been suggested to induce MMP-1 mRNA expression in fibroblasts, and sublethal exposure to hydrogen peroxide has been found to increase the expression and activation of MMP-2 in human endothelial cells [107] The treatment of fibroblasts with xanthine/xanthine oxides results in the induction of MMP-2 and MMP-9; furthermore, superoxidestimulated extracellular signal-regulated kinase activation has been shown to mediate MMP-9 induction in vascular smooth muscle cells [108]. Studies using genetically manipulated mice have suggested that superoxide and/or hydrogen peroxide are involved in the induction and activation of MMPs [109]. These studies have strongly implied that superoxide and/or hydrogen peroxide might mediate BBB disruption through the activation of MMPs. Studies have also shown that excessive production of superoxide radicals result in increased water and sodium content in the brain and the extravasation of Evans blue, suggesting the development of vasogenic edema [110]. Moreover, the superoxide radical has been identified as the primary radical involved in increased vascular permeability and edema development in various disease models [111]. Based on the amount of evidence, it is clear that free radicals, and the resulting oxidative stress, are involved in $\mathrm{BBB}$ disruption and brain injury after stroke. The challenging task in the future is to how to attenuate free radical damage at the cellular and molecular level.

\section{Membrane metalloproteinases in vascular damage: a potential drug target}

This section will continue with the theme of MMPs, which are a group of important proteolytic enzymes whose catalytic mechanism involves a metal. MMPs are zinc- and calcium-dependent endopeptidases which are known to degrade many components of the extracellular matrix (ECM) including fibronectin, laminin, proteoglycans and type IV collagen [112,113]. They have been categorized into four groups of enzymes based on protein structure: collagenases, stromelysins, gelatinases, and membrane-type MMPs [114]. These enzymes are secreted as a latent form, but once they become activated they regulate many physiological and pathological processes. Cytokines, such as TNFa and IL-1 induce the transcription of MMP-3 and MMP-9 which are important in both acute and chronic neuroinflammation. In addition, several activation mechanisms have been suggested including other proteases and free radicals $[104,115]$. The activity of MMPs might be controlled by free radicals, either through activation of the latent forms or by induction of mRNA through signaling via the nuclear factor-kappaB site [116].

Many investigators have emphasized the role MMP-2, 3, 9, and 12 in ICH $[18,22,25,75,90,117]$. Firstly, a study has demonstrated that activation of MMP-2 and MMP-9 was increased after collagenaseinduced ICH in rats[18]. Subsequently, another study has indicated that brain MMP-2, 3, 7, 9 and 12 mRNA levels were increased in collagenase-induced hemorrhage rat model [75]. Furthermore, a dramatic increase of MMP-9 activity was observed by gel and in situ zymography in collagenase-induced hemorrhage rat model [22]. Moreover, early increases in MMP-9 mRNA and activity have been confirmed in other animal ICH models including mouse [25] and pig 
[117]. The findings are consistent and show that MMP's were regulated by hemorrhage and also played a crucial role in vascular damage. Similarly, several clinical studies have reported an evaluation of MMP9 levels in blood of patients with ICH [118-120]. Taken together, these data support the view that some of the MMPs, especially MMP-3, 9, and 12 , might play an important role in the pathophysiology of ICH.

Cellular components of the BBB include endothelium, pericytes/ microglia and the perivascular astrocytic processes. Previous studies have shown that astrocytes, neurons, oligodendroglia, endothelial cells, pericytes, and microglia produce MMPs [121,122]. Mixed microglia and astrocytes in culture produce an active form of MMP-9, whereas astrocytes alone in culture induces proMMP-9 but failed to produce the active form of MMP-9. Moreover, immunostaining of mixed glial cultures showed that MMP-3 was expressed by microglia, but not by astrocytes. This finding suggested that the microglia-derived MMP3 was critical for activation of the MMP-9 during the inflammatory response. Activation of the proMMPs is central in the proteolytic process. In cell cultures, microglia interact with the pericytes, endothelial cells and astrocytes to activate MMPs. Therefore, microglia may be necessary for the activation of the proMMP-9 which could be done by MMP-3.

As mentioned above, inflammatory mediators, such as TNF- $\alpha$ and IL- $1 \beta$, induce the production of the MMPs. In addition, activation processes of MMPs involve proteases and free radicals. Therefore, microglia and tissue macrophages play a critical role in the inflammatory response both by releasing the MMPs and by forming molecules that activate them. Previous studies have shown that TNF- $\alpha$ stimulates cells to produce active MMPs, which facilitate leukocyte extravasation and brain edema by degradation of extracellular matrix components and the opening of the BBB that could be blocked by the use of the MMP inhibitor [123]. Astrocytic end feet and tight-junctioned endothelial cells act in concert with the basal lamina and the pericytes/microglia to form $\mathrm{BBB}$ as a neurovascular unit. The tight junctions of the endothelial cells comprise the first line of defense. Basal lamina forms a layer around the endothelial cells to provide a charged barrier and may impede diffusion of larger molecules. MMPs affect the function of the neurovascular structures by degrading the components of the basal lamina around the cerebral vessels to increase the permeability of the $\mathrm{BBB}$, thereby contributing to brain edema and hemorrhagic brain injury $[18,92]$. Overall, MMPs cause increase in permeability of the $\mathrm{BBB}$ by targeting the matrix proteins, resulting in the final common pathway downstream of acute neuroinflammatory damage to induce the vasogenic edema. Research evidence suggests that the development and use of specific MMP inhibitors may reduce hemorrhage expansion, vascular damage and ischemic damage.

\section{Potential targets to treat brain hemorrhage}

Some important, but very preliminary steps toward therapeutics for hemorrhage have been made using preclinical animal models. Therapies aimed at reducing the cascade of injuries surrounding a hemorrhage may reduce the deleterious effects of hemorrhage including edema, apoptotic and necrotic cell death. As describe above, there are many key processes involved in hemorrhage and the deficits that occur subsequent to hemorrhage. Inflammatory reactions, free radicals, BBB damage and edema are primary targets for useful hemorrhage treatments. This section will identify a few targets that should be further pursued.

\section{Anti-inflammatory drugs}

When ICH occurs, blood components including erythrocytes, leukocytes, macrophages, and plasma proteins (thrombin and plasmin) immediately enter the brain. Therefore, brain tissue injury occurs after an inflammatory reaction which comprises both cellular and molecular components. Anti-inflammatory strategies have been tested in previous studies. As discussed above, there are detrimental effects of microglial activation in ICH-induced brain injury [124]. Therefore, it seems that there exists the therapeutic potential of treatments based on the inhibition of microglial activation shortly after the onset of ICH. In previous studies, tuftsin fragment 1-3 macrophage/microglial inhibitory factor (MIF) inhibited microglial activation and macrophage infiltration following collagenase-induced ICH $[26,74]$. The treatment also reduced stroke injury volume and improved behavior. These findings further support that microglial activation promotes inflammatory reactions after ICH and MIF could be a valuable neuroprotective agent for the treatment of $\mathrm{ICH}$. Furthermore, another study using a rodent ICH model showed that antileukocyte intervention reduced neutrophil infiltration, behavioral deficits and neuronal damage [125]. Therefore, the strategies targeting leukocytes and microglial activation may merit further evaluation either as alternative or adjunctive therapeutic approach to ICH.

\section{TNF and MMP's}

Activation of cytokines is an important component in the cascade of events that lead to damage following a stroke. Mature pro-TNFa can be cleaved to biologically active TNFa by several membrane MMP's, one which is known as TNF-alpha-converting enzyme (TACE) [126130]. While MMP's are involved in the processing of pro-TNFa, mature TNFa can also induce MMP-9 in the CNS $[16,18,21,131,132]$ which perpetuates the cycle of TNF $\alpha$ production that can result in membrane damage [122]. Synthesis of TNFa from pro-TNFa is blocked by MMP inhibitors like BB-2284 [133], BB-94 [134-136] as well as specific TACE inhibitors such as Ro32-7315[137] and DPH-067517[138]. A previous study showed that $\mathrm{ICH}$ can be reduced by administration of a non-specific MMP inhibitor BB-94 in a rat collagenase model [18]. In the RLCEM, the MMP inhibitor BB-94 also lowered the rate of tPAinduced hemorrhage, while not affecting significantly hemorrhage rate in the absence of tPA administration [45]. It is interesting to note that BB-94 could reduce TNFa levels in rabbit brain even though BB-94 is a non-selective MMP inhibitor [139]. Also, other groups have reported that BB-94 can reduce tissue levels of TNFa [134-136]. The reduction in hemorrhage rate consequent to BB-94 administration is consistent with the previously described role of MMP's as important factors in the $\mathrm{BBB}$ vasculature function and extracellular matrix remodeling following a stroke [121] but may also expand the roles of processing TNFa. Of particular promise are MMP-9 inhibitors that have recently been shown to reduce brain injury and apoptosis following $\mathrm{SAH}$ $[140,141]$.

There is some evidence in ischemic stroke and hemorrhage patients that MMP-2 and MMP-9 may be involved either BBB breakdown or remodeling following the injury. In stroke patients, serum MMP-2 and MMP-9 levels increased during the course of ischemia [142,143]. In SAH patients serum MMP-2 levels from SAH patients MMP-2 levels are significantly decreased while MMP-9 levels are increased relative to controls. MMP-2 levels remain decreased 12 days post SAH, but MMP-9 levels appeared to recover [142,143]. There is also evidence linking MMP-2 to SAH from intracranial aneurysm rupture[144], which substantiates the hypothesis that MMP-2 and/or MMP-9 may be directly involved in the progression of stroke and hemorrhage. In a post-mortem study, there was increased endothelial expression of both MMP-2 and MMP-9 suggesting that endothelial expression of MMPs 
may affect vascular matrix stability and contribute to hemorrhage [145]. The results from preclinical studies suggest that MMP's and possibly TNFa are directly involved in blood barrier breakdown and hemorrhage in brain following a variety of insults. MMP-2, MMP-9 and TACE are all valid targets for the development of small molecules to reduce spontaneous $\mathrm{ICH}, \mathrm{SAH}$ or hemorrhage resulting from the administration of thrombolytics.

Interleukin-1 has gained attention as a therapeutic target for stroke because extensive evidence support the direct involvement of interleukin-1 in the neuronal injury that occurs in acute neurodegeneration [146]. Studies have shown that inhibiting IL-1 release or activity markedly reduces ischemic cerebral and cerebral hemorrhagic damage [147]. Moreover, previous studies have reported that over expression of interleukin-1 receptor antagonist (IL-1ra) attenuated brain edema formation and thrombin-induced intracerebral inflammation in a rat autologous blood injection model of ICH $[148,149]$. Therefore, these studies suggested that IL-1ra could be considered as a potential therapeutic agent for patients with ICH and could be the focus of additional preclinical and clinical research.

\section{Free radical scavengers}

Free radicals have been proposed to mediate an array of injuries following a stroke [150-156]. Reactive oxygen species cause brain injury via many different pathways. Compounds that can counteract or reverse the effects of free radicals have received a great deal of attention in recent years. Edaravone (3-methyl-1-phenyl-2-pyrazolin-5-one) is a potent lipid soluble hyrdoxyl and peroxyl radical scavenger used clinically for treatment of ischemic stroke in Japan. Previous study has shown that edaravone attenuated ICH-induced brain edema, neurologic deficits, and oxidative injury and also reduced iron- and thrombin-induced brain injury, suggesting that edaravone is a potential therapeutic agent for ICH [157]. Moreover, the edaravone clinical trial [158] reported that there was a significant improvement in functional outcome as evaluated using the modified Rankin Scale, when treatment was started within $72 \mathrm{hr}$ of onset. Furthermore, another study reported preliminary findings of a clinical trial showing that patients treated with edaravone prior to administration of intravenous tPA had a reduced incidence of ICH compared with placebo-treated tPA-treated patients [159]. Thus, edaravone, or other lipophilic free radical scavengers may be useful to treat either acute ischemic stroke or hemorrhagic stroke.

Also, other studies have attempted to target pro-oxidant heme or iron to recue a potential source of ROS production during hemorrhage. It is postulated that the regulation of $\mathrm{HO}$ might decrease $\mathrm{ICH}$-induced toxicity because the enzyme metabolizes heme to release iron [160]. Several studies have also shown that nonselective inhibitors of HO (tin-mesoporphyrin IX, tin-protoporphyrin, and zinc protoporphyrin) decreased ICH-induced brain edema and neurologic deficits $[30,97,161,162]$. Moreover, a ferric iron chelator (Deferoxamine) was shown to have a similar neuroprotective effect after ICH $[96,163]$, suggesting that ROS could be a potential target for ICH therapy. Furthermore, the effect of melatonin, a potent antioxidant and freeradical scavenger, on outcomes was investigated in rat collagenaseinduced ICH model. The results showed that brain edema and neurological function at $24 \mathrm{~h}$ were unchanged in spite of oxidative stress reductions. However, repeated treatment with the lower dose of melatonin $(5 \mathrm{mg} / \mathrm{kg})$ given at $1 \mathrm{~h}$ and every $24 \mathrm{~h}$ thereafter for 3 days after ICH, led to normalization of striatal function, normalized memory tasks and reduced brain atrophy, suggesting that melatonin is safe for use after ICH and is protective [164].

\section{New treatment possibilities}

The following section will review new pharmacological agents still in early stages of development. However, since some of the most important recent advances have been non-pharmaceutical in nature, they will be highlighted below. Many of the novel treatments have the potential to reduce hemorrhage and may be the hemorrhage treatment of the future.

\section{Brain Hypothermia (BH)}

The secondary consequences of ICH including inflammation, edema, and oxidative damage all contribute to cell death after ICH. Preclinically, brain hypothermia (BH) has been used as an effective neuroprotective treatment in experimental brain ischemia and traumatic brain injury [165-168]. Before reviewing the intriguing results, $\mathrm{BH}$ must be defined. $\mathrm{BH}$ is now classified by the depth of cooling below normal body temperature (i.e. $37-38^{\circ} \mathrm{C}$ ). Mild hypothermia reduces body temperature by $3-6^{\circ} \mathrm{C}$, whereas deep hypothermia reduces body temperature by $10^{\circ} \mathrm{C}$ [169]. Although there is no consensus on an optimal temperature, the largest neuroprotective benefit is obtained with $34^{\circ} \mathrm{C}$ [170]. Neuroprotection by mild hypothermia is associated with mitochondrial preservation and suppression of apoptosis. Pathophysiological mechanisms involved in the beneficial effects of hypothermia are being elucidated [171]. Evidence suggests that significant metabolic downregulation including attenuation of the inflammatory response and reduced reactive oxygen species may be the basis for neuroprotection [171,172]. Suppression of both can reduce the activity of MMP's to prevent $\mathrm{BBB}$ damage and edema $[173,174]$. Mild BH significantly reduces the brain edema formation after ICH and several neuroprotective mechanisms including reduced $\mathrm{BBB}$ disruption, inflammation and oxidative damage are suggested in this study [175]. Because preclinical studies are promising, the recommendation by Groysman [176], should be followed. Clearly, trials are warranted to define the specific operating conditions for effective hypothermia including the therapeutic window and temperature regimen [169]. Clinical trials of hypothermia for stroke (ICTuS-L trial) have had mixed results. A recent study showed the feasibility of hypothermia in stroke patients, but there were significant side effects related to the treatment. Pneumonia occurred in $50 \%$ of hypothermic patients compared to $10 \%$ of normothermic patients $(\mathrm{p}=0.001)$; however, there was an almost equal number of deaths in both groups $(p>0.05)$ [177]. The results raise the following question: Is $\mathrm{BH}$ a cool method of neuroprotection or will the side effects limit its use? Only additional studies will be able to provide an answer.

\section{Hyperbaric Oxygen (HBO)}

Hyperbaric oxygen ( $\mathrm{HBO}$ ), $100 \% \mathrm{O}_{2}$ at 3 bar or ATA [178] is a promising non-invasive method to decrease $\mathrm{BBB}$ damage, reduce hemorrhagic transformation and reduce hemoglobin extravasation in ischemic zones following embolic stroke [178]. Moreover, HBO has been found to reduce thrombolytic-induced hemorrhage [178]. Investigators have found that $\mathrm{HBO}$ has diverse effects[179,180] including reduced non-thrombin mediated edema, and edema reduction mediated by activation of ribosomal protein S6 kinases ( $\mathrm{p} 70$ S6 K), which are important to protein synthesis [180]. Furthermore, Ostrowski et al. [181,182], who extensively studied mechanisms of HBO in models of $\mathrm{SAH}$, showed that $\mathrm{HBO}$-induced reduced mortality and behavioral improvement was somewhat correlated with reduced lipid peroxidation measured by detecting malondialdehyde, the degradation product of polyunsaturated lipids. HBO treatment also reduced the expression superoxide producing enzyme, NADPH oxidase (NOX) 
Citation: Lapchak PA, Wu Q (2011) Vascular Dysfunction in Brain Hemorrhage: Translational Pathways to Developing New Treatments from Old Targets. J Neurol Neurophysiol S1. doi:10.4172/2155-9562.S1-e001

[182]. The study suggests that HBO decreases oxidative stress via an early inhibition of NOX. Matchett et al.[183] reviewed the use of HBO and suggested that the treatment has mainly positive effects in animal models, since $\mathrm{HBO}$ reduces $\mathrm{BBB}$ breakdown, decreases inflammation and oxidative stress, reduces edema and suppresses apoptosis [184].

\section{Normobaric oxygen (NBO)}

Normobaric oxygen (NBO) therapy has been studied by Lo and colleagues to treat both stroke and hemorrhage [185-187]. Like HBO, NBO, $100 \% \mathrm{O}_{2}$ has some neuroprotective effects. Most work has been done in embolic stroke, rather than hemorrhagic stroke models. Lo and colleagues [186] showed that NBO could be safely administered with tPA in a rat embolic stroke model, leading the way for additional studies and clinically relevant measures. A follow-up study by Sun et al. [178] using a thrombin-induced hemorrhage model showed that $\mathrm{NBO}$ decreases infarct size and tPA-induced hemorrhage. In the same study, in parallel rats, they found that HBO reduced hemoglobin extravasation in the ischemic brain. Moreover, both $\mathrm{NBO}$ and $\mathrm{HBO}$ treatment decreased $\mathrm{BBB}$ damage and the incidence of hemorrhagic transformation. In a hemorrhage model, $\mathrm{NBO}$ did not affect collagenase-induced blood volume or edema and was ineffective at reducing neurological outcome [185]. Interpretation of a negative study using a single treatment regimen and is quite difficult, especially given the fact that the study was uncontrolled (i.e. no positive control). It is premature to definitively conclude that NBO treatment is ineffective to teat hemorrhagic stroke until various treatment regimens are tested in parallel in multiple hemorrhage models with proper positive controls in each study [188].

\section{Hydrogen gas (HG)}

A novel and quite interesting observation was recently made by Chen et al. [189] and Zhang et al. [190]. The discovery seems to tie together many of the key mechanisms described above including free radicals, oxidative stress and MMP's. The authors showed that hydrogen gas by inhalation can exert neuroprotective effects and reduce hemorrhagic transformation following MCA occlusion. It is hypothesized that $\mathrm{H}_{2}$ gas decreases oxidative stress and reduces MMP9 activation and/or activity.

\section{Conclusion}

ICH will continue to be an important problem as the population ages in the United States and worldwide. As can be gleaned from this article, there are many suitable targets for drug development including inhibition of specific MMP's, TNFa, thrombin, inflammation and the coagulation pathway. Many preliminary attempts at monotherapy have not been effective. This is most likely due to simultaneous activation of a "hemorrhage cascade" and a "stroke cascade" with some overlapping key mediators $[51,66,93,191,192]$. There is a growing consensus that the treatment of ischemic stroke will require pleiotropic drugs or combination therapy [93,193-200]. This may be even more crucial when one considers the effect of brain blood on tissue plus the fact that brain bleeds will cause tissue ischemia and edema. For hemorrhage treatment, the following drug classes hold promise for an eventual treatment: anti-inflammatory drugs, anti-oxidants, thrombin, and HO inhibitors. Surprisingly, some of the most effective preclinical treatments are noninvasive therapies such as hyperthermia, HBO, NBO and HG. Although it is early in their development and investigation, they are all pleiotropic therapies that have multiple physiological consequences. Continued mechanism-based research and translational research will provide a better understanding of the mechanisms involved in hemorrhagic stroke so that preclinical knowledge can be translated into a clinically useful therapeutic.

\section{Acknowledgments and Funding}

This article was supported by a U01 Translational research grant NS060685 to PAL. There are no conflicts of interest to disclose.

\section{Reference}

1. Lloyd-Jones D, Adams R, Carnethon M, Ferguson B, Flegal K, et al. (2009) Heart disease and stroke statistics--2009 update: a report from the American Heart Association Statistics Committee and Stroke Statistics Subcommittee. Circulation 119: 480-486.

2. Lloyd-Jones D, Adams RJ, Brown TM, Carnethon M, Dai S, et al. (2010) Executive summary: heart disease and stroke statistics--2010 update: a report from the American Heart Association. Circulation 121: 948-954.

3. Lloyd-Jones D, Adams RJ, Brown TM, Carnethon M, Dai S, et al. (2010) Heart disease and stroke statistics--2010 update: a report from the American Heart Association. Circulation 121: e18-e209.

4. Lapchak PA (2002) Hemorrhagic transformation following ischemic stroke: significance, causes, and relationship to therapy and treatment. Curr Neurol Neurosci Rep 2: 38-43

5. Lyden PD, Zivin JA (1993) Hemorrhagic transformation after cerebral ischemia: mechanisms and incidence. Cerebrovasc Brain Metab Rev 5: 1-16.

6. Bernstein RA, Del-Signore M (2005) Recent advances in the management of acute intracerebral hemorrhage. Curr Neurol Neurosci Rep 5: 483-487.

7. van Gijn J, Kerr RS, Rinkel GJ (2007) Subarachnoid haemorrhage. Lancet 369: 306-318.

8. Toni D, Fiorelli M, Bastianello S, Sacchetti ML, Sette G, et al. (1996) Hemorrhagic transformation of brain infarct: predictability in the first 5 hours from stroke onset and influence on clinical outcome. Neurology 46: 341-345.

9. Donnan GA (2008) Stroke. Lancet 371: 1612-1623.

10. Berwaerts J, Robb OJ, Dykhuizen RS, Webster J (2000) Course, management and outcome of oral-anticoagulant-related intracranial haemorrhages. Scott Med J 45: 105-109.

11. Flaherty ML, Kissela B, Woo D, Kleindorfer D, Alwell K, et al. (2007) The increasing incidence of anticoagulant-associated intracerebral hemorrhage. Neurology 68: 116-121.

12. Khatri $P$, Wechsler LR, Broderick JP (2007) Intracranial hemorrhage associated with revascularization therapies. Stroke 38: 431-440.

13. Jackson-Friedman C, Lyden PD, Nunez S, Jin A, Zweifler R (1997) High dose baclofen is neuroprotective but also causes intracerebral hemorrhage: a quantal bioassay study using the intraluminal suture occlusion method. Exp Neurol 147: 346-352.

14. Lyden P, Shin C, Jackson-Friedman C, Hassid S, Chong A, et al. (2000) Effect of ganaxolone in a rodent model of cerebral hematoma. Stroke 31: 169-175.

15. Lyden PD, Jackson-Friedman C, Lonzo-Doktor L (1997) Medical therapy for intracerebral hematoma with the gamma-aminobutyric acid-A agonis muscimol. Stroke 28: 387-391.

16. Rosenberg GA (1995) Matrix metalloproteinases in brain injury. J Neurotrauma 12: 833-842.

17. Rosenberg GA, Estrada EY, Dencoff JE, Stetler-Stevenson WG (1995) Tumor necrosis factor-alpha-induced gelatinase $B$ causes delayed opening of the blood-brain barrier: an expanded therapeutic window. Brain Res 703: 151-155

18. Rosenberg GA, Navratil M (1997) Metalloproteinase inhibition blocks edema in intracerebral hemorrhage in the rat. Neurology 48: 921-926.

19. Rosenberg GA, Bryce SM, Wesley M, Kornfeld M (1990) Collagenase-induced intracerebral hemorrhage in rats. Stroke 21: 801-807.

20. Rosenberg GA, Estrada E, Wesley M, Kyner WT (1990) Autoradiographic patterns of brain interstitial fluid flow after collagenase-induced haemorrhage in rat. Acta Neurochir Suppl (Wien) 51: 280-282.

21. Romanic AM, White RF, Arleth AJ, Ohlstein EH, Barone FC (1998) Matrix metalloproteinase expression increases after cerebral focal ischemia in rats: inhibition of matrix metalloproteinase-9 reduces infarct size. Stroke 29: 10201030. 
Citation: Lapchak PA, Wu Q (2011) Vascular Dysfunction in Brain Hemorrhage: Translational Pathways to Developing New Treatments from Old Targets. J Neurol Neurophysiol S1. doi:10.4172/2155-9562.S1-e001

22. Wang J, Tsirka SE (2005) Neuroprotection by inhibition of matrix metalloproteinases in a mouse model of intracerebral haemorrhage. Brain 128: 1622-1633.

23. Kitaoka T, Hua Y, Xi G, Hoff JT, Keep RF (2002) Delayed argatroban treatment reduces edema in a rat model of intracerebral hemorrhage. Stroke 33: 30123018.

24. Kitaoka T, Hua Y, Xi G, Nagao S, Hoff JT, et al. (2003) Effect of delayed argatroban treatment on intracerebral hemorrhage-induced edema in the rat. Acta Neurochir Suppl 86: 457-461.

25. Tang J, Liu J, Zhou C, Alexander JS, Nanda A, et al. (2004) MMP-9 deficiency enhances collagenase-induced intracerebral hemorrhage and brain injury in mutant mice. J Cereb Blood Flow Metab 24: 1133-1145.

26. Wang J, Rogove AD, Tsirka AE, Tsirka SE (2003) Protective role of tuftsin fragment 1-3 in an animal model of intracerebral hemorrhage. Ann Neurol 54 655-664

27. Brott T, Broderick J, Kothari R, Barsan W, Tomsick T, et al. (1997) Early hemorrhage growth in patients with intracerebral hemorrhage. Stroke 28: 1-5.

28. Kazui S, Naritomi H, Yamamoto H, Sawada T, Yamaguchi T (1996) Enlargement of spontaneous intracerebral hemorrhage. Incidence and time course. Stroke 27: $1783-1787$

29. Gu Y, Hua Y, Keep RF, Morgenstern LB, Xi G (2009) Deferoxamine reduces intracerebral hematoma-induced iron accumulation and neuronal death in piglets. Stroke 40: 2241-2243.

30. Koeppen AH, Dickson AC, Smith J (2004) Heme oxygenase in experimental intracerebral hemorrhage: the benefit of tin-mesoporphyrin. J Neuropathol Exp Neurol 63: 587-597.

31. Okauchi M, Hua Y, Keep RF, Morgenstern LB, Xi G (2009) Effects of deferoxamine on intracerebral hemorrhage-induced brain injury in aged rats. Stroke 40: 1858-1863.

32. Qureshi Al, Suri MF, Ling GS, Khan J, Guterman LR, et al. (2001) Absence of early proinflammatory cytokine expression in experimental intracerebral hemorrhage. Neurosurgery 49: 416-420.

33. Rynkowski MA, Kim GH, Komotar RJ, Otten ML, Ducruet AF, et al. (2008) A mouse model of intracerebral hemorrhage using autologous blood infusion. Nat Protoc 3: 122-128.

34. Tejima E, Zhao BQ, Tsuji K, Rosell A, van Leyen K, et al. (2007) Astrocytic induction of matrix metalloproteinase- 9 and edema in brain hemorrhage. $J$ Cereb Blood Flow Metab 27: 460-468.

35. Wang J, Fields J, Dore S (2008) The development of an improved preclinical mouse model of intracerebral hemorrhage using double infusion of autologous whole blood. Brain Res 1222: 214-221.

36. Xue M, Hollenberg MD, Yong VW (2006) Combination of thrombin and matrix metalloproteinase- 9 exacerbates neurotoxicity in cell culture and intracerebral hemorrhage in mice. J Neurosci 26: 10281-10291.

37. Zhao X, Sun G, Zhang J, Strong R, Song W, et al. (2007) Hematoma resolution as a target for intracerebral hemorrhage treatment: role for peroxisome proliferator-activated receptor gamma in microglia/macrophages. Ann Neurol 61: 352-362

38. Sugawara T, Ayer R, Jadhav V, Chen W, Tsubokawa T, et al. (2008) Simvastatin attenuation of cerebral vasospasm after subarachnoid hemorrhage in rats via increased phosphorylation of Akt and endothelial nitric oxide synthase. J Neurosci Res 86: 3635-3643.

39. Sugawara T, Ayer R, Jadhav V, Zhang JH (2008) A new grading system evaluating bleeding scale in filament perforation subarachnoid hemorrhage rat model. J Neurosci Methods 167: 327-334.

40. Sugawara T, Jadhav V, Ayer R, Chen W, Suzuki H, et al. (2009) Thrombin inhibition by argatroban ameliorates early brain injury and improves neurological outcomes after experimental subarachnoid hemorrhage in rats. Stroke 40 1530-1532.

41. Sugawara T, Jadhav V, Ayer R, Zhang J (2008) Simvastatin attenuates cerebral vasospasm and improves outcomes by upregulation of PI3K/Akt pathway in a rat model of subarachnoid hemorrhage. Acta Neurochir Suppl 102: 391-394.

42. Lapchak PA, Araujo DM (2001) Reducing bleeding complications after thrombolytic therapy for stroke: clinical potential of metalloproteinase inhibitors and spin trap agents. CNS Drugs 15: 819-829.
43. Lapchak PA (2002) Effects of the spin trap agent disodium- [tert- butylimino) methyl]benzene-1,3-disulfonate $\mathrm{N}$-oxide (generic NXY-059) on intracerebra hemorrhage in a rabbit Large clot embolic stroke model: combination studies with tissue plasminogen activator. Stroke 33: 1665-1670.

44. Lapchak PA, Araujo DM, Song D, Zivin JA (2002) The nonpeptide glycoprotein Ilb/Illa platelet receptor antagonist SM-20302 reduces tissue plasminogen activator-induced intracerebral hemorrhage after thromboembolic stroke. Stroke 33: 147-152.

45. Lapchak PA, Chapman DF, Zivin JA (2000) Metalloproteinase inhibition reduces thrombolytic (tissue plasminogen activator)-induced hemorrhage after thromboembolic stroke. Stroke 31: 3034-3040.

46. Lyden PD, Madden KP, Clark WM, Sasse KC, Zivin JA (1990) Incidence of cerebral hemorrhage after treatment with tissue plasminogen activator or streptokinase following embolic stroke in rabbits [corrected]. Stroke 21: 15891593.

47. Lyden PD, Zivin JA, Soll M, Sitzer M, Rothrock JF, Alksne J (1987) Intracerebra hemorrhage after experimental embolic infarction. Anticoagulation. Arch Neuro 44: 848-850.

48. Brott T, Adams HP, Olinger CV, Marler JR, Barsan WG, et al. (1989) Measurements of acute cerebral infarction: a clinical examination scale. Stroke 20: 864-870.

49. Lyden PD, Zivin JA, Clark WA, Madden K, Sasse KC, Mazzarella VA, et al. (1989) Tissue plasminogen activator-mediated thrombolysis of cerebral emboli and its effect on hemorrhagic infarction in rabbits. Neurology 39: 703-708.

50. Bowes MP, Zivin JA, Thomas GR, Thibodeaux H, Fagan SC (1996) Acute hypertension, but not thrombolysis, increases the incidence and severity of hemorrhagic transformation following experimental stroke in rabbits. Exp Neurol 141: 40-46.

51. Xi G, Keep RF, Hoff JT (2006) Mechanisms of brain injury after intracerebral haemorrhage. Lancet Neurol 5: 53-63

52. Lok J, Leung W, Murphy S, Butler W, Noviski N, et al. (2011) Intracrania hemorrhage: mechanisms of secondary brain injury. Acta Neurochir Suppl 111 63-69.

53. Fujimoto S, Katsuki H, Ohnishi M, Takagi M, Kume T, et al. (2008) Plasminogen potentiates thrombin cytotoxicity and contributes to pathology of intracerebra hemorrhage in rats. J Cereb Blood Flow Metab 28: 506-515.

54. You H, Al-Shahi R (2006) Haemostatic drug therapies for acute primary intracerebral haemorrhage. Cochrane Database Syst Rev 3: CD005951.

55. Lwaleed BA, Goyal A, Delves GH, Cooper AJ (2007) Seminal hemostatic factors: then and now. Semin Thromb Hemost 33: 3-12.

56. Hoots WK (2006) Challenges in the Therapeutic Use of a "So-Called" Universa Hemostatic Agent: Recombinant Factor VIla. Hematology Am Soc Hematol Educ Program 426-431.

57. Hedner U, Lee CA (2011) First 20 years with recombinant FVIla (NovoSeven) Haemophilia 17: e172-182.

58. Traynelis SF, Trejo J (2007) Protease-activated receptor signaling: new roles and regulatory mechanisms. Curr Opin Hematol 14: 230-235.

59. Coughlin SR (2005) Protease-activated receptors in hemostasis, thrombosis and vascular biology. J Thromb Haemost 3: 1800-1814.

60. Soh UJ, Dores MR, Chen B, Trejo JA (2010) Signal transduction by proteaseactivated receptors. Br J Pharmacol 160: 191-203.

61. Katsuki H (2010) Exploring neuroprotective drug therapies for intracerebral hemorrhage. J Pharmacol Sci 114: 366-378.

62. Lee KR, Kawai N, Kim S, Sagher O, Hoff JT (1997) Mechanisms of edema formation after intracerebral hemorrhage: effects of thrombin on cerebral blood flow, blood-brain barrier permeability, and cell survival in a rat model. $J$ Neurosurg 86: 272-278.

63. Chen B, Cheng Q, Yang K, Lyden PD (2010) Thrombin mediates severe neurovascular injury during ischemia. Stroke 41: 2348-2352.

64. Liu DZ, Ander BP, Xu H, Shen Y, Kaur P, et al. (2010) Blood-brain barrier breakdown and repair by Src after thrombin-induced injury. Ann Neurol 67 526-533.

65. Liu DZ, Tian Y, Ander BP, Xu H, Stamova BS, et al. (2010) Brain and blood 
Citation: Lapchak PA, Wu Q (2011) Vascular Dysfunction in Brain Hemorrhage: Translational Pathways to Developing New Treatments from Old Targets. J Neurol Neurophysiol S1. doi:10.4172/2155-9562.S1-e001

microRNA expression profiling of ischemic stroke, intracerebral hemorrhage, and kainate seizures. J Cereb Blood Flow Metab 30: 92-101.

66. Wang J, Dore S (2007) Inflammation after intracerebral hemorrhage. J Cereb Blood Flow Metab 27: 894-908.

67. Wang J (2010) Preclinical and clinical research on inflammation after intracerebral hemorrhage. Prog Neurobiol 92: 463-477.

68. Wang J, Tsirka SE (2005) Contribution of extracellular proteolysis and microglia to intracerebral hemorrhage. Neurocrit Care 3: 77-85.

69. Stoll G, Schroeter M, Jander S, Siebert H, Wollrath A, et al. (2004) Lesionassociated expression of transforming growth factor-beta-2 in the rat nervous system: evidence for down-regulating the phagocytic activity of microglia and macrophages. Brain Pathol 14: 51-58.

70. Gregersen R, Lambertsen K, Finsen B (2000) Microglia and macrophages are the major source of tumor necrosis factor in permanent middle cerebral artery occlusion in mice. J Cereb Blood Flow Metab 20: 53-65.

71. Hanisch UK (2002) Microglia as a source and target of cytokines. Glia 40: 140155.

72. Banno M, Mizuno T, Kato H, Zhang G, Kawanokuchi J, et al. (2005) The radical scavenger edaravone prevents oxidative neurotoxicity induced by peroxynitrite and activated microglia. Neuropharmacology 48: 283-290.

73. Min KJ, Yang MS, Kim SU, Jou I, Joe EH (2006) Astrocytes induce hemeoxygenase-1 expression in microglia: a feasible mechanism for preventing excessive brain inflammation. J Neurosci 26: 1880-1887.

74. Wang J, Tsirka SE (2005) Tuftsin fragment 1-3 is beneficial when delivered after the induction of intracerebral hemorrhage. Stroke 36: 613-618.

75. Power C, Henry S, Del Bigio MR, Larsen PH, Corbett D, et al. (2003) Intracerebral hemorrhage induces macrophage activation and matrix metalloproteinases. Ann Neurol 53: 731-742.

76. Nguyen HX, O'Barr TJ, Anderson AJ (2007) Polymorphonuclear leukocytes promote neurotoxicity through release of matrix metalloproteinases, reactive oxygen species, and TNF-alpha. J Neurochem 102: 900-912.

77. Joice SL, Mydeen F, Couraud PO, Weksler BB, Romero IA, et al (2009) Modulation of blood-brain barrier permeability by neutrophils: in vitro and in vivo studies. Brain Res 1298: 13-23.

78. Barone FC, Feuerstein CZ (1999) Inflammatory mediators and stroke: new opportunities for novel therapeutics. J Cereb Blood Flow Metab 19: 819-834.

79. Emsley HC, Tyrrell PJ (2002) Inflammation and infection in clinical stroke. J Cereb Blood Flow Metab 22: 1399-1419.

80. Aronowski J, Hall CE (2005) New horizons for primary intracerebral hemorrhage treatment: experience from preclinical studies. Neurol Res 27: 268-279.

81. Zhang D, Hu X, Qian L, Wilson B, Lee C, et al. (2009) Prostaglandin E2 released from activated microglia enhances astrocyte proliferation in vitro. Toxicol Appl Pharmacol 238: 64-70.

82. Burger D, Dayer JM (2002) Cytokines, acute-phase proteins, and hormones: IL-1 and TNF-alpha production in contact-mediated activation of monocytes by T lymphocytes. Ann N Y Acad Sci 966: 464-473.

83. Hua Y, Wu J, Keep RF, Nakamura T, Hoff JT, et al. (2006) Tumor necrosis factor-alpha increases in the brain after intracerebral hemorrhage and thrombin stimulation. Neurosurgery 58: 542-550.

84. Mayne M, Ni W, Yan HJ, Xue M, Johnston JB, et al. (2001) Antisense oligodeoxynucleotide inhibition of tumor necrosis factor-alpha expression is neuroprotective after intracerebral hemorrhage. Stroke 32: 240-248.

85. Xi G, Hua Y, Keep RF, Younger JG, Hoff JT (2001) Systemic complement depletion diminishes perihematomal brain edema in rats. Stroke 32:162-167.

86. Lapchak PA (2007) Tumor necrosis factor-alpha is involved in thrombolyticinduced hemorrhage following embolic strokes in rabbits. Brain Res 1167: 123-

87. Eigler A, Sinha B, Hartmann G, Endres S (1997) Taming TNF: strategies to restrain this proinflammatory cytokine. Immunol Today, 1997 18: 487-492.

88. Feuerstein G, Wang X, Barone FC (1998) Cytokines in brain ischemia--the role of TNF alpha. Cell Mol Neurobiol 18: 695-701.

89. Wagner KR, Beiler S, Beiler C, Kirkman J, Casey K, et al. (2006) Delayed profound local brain hypothermia markedly reduces interleukin-1beta gene expression and vasogenic edema development in a porcine model of intracerebral hemorrhage. Acta Neurochir Suppl 96: 177-182.

90. Lu A, Tang Y, Ran R, Ardizzone TL, Wagner KR, et al. (2006) Brain genomics of intracerebral hemorrhage. J Cereb Blood Flow Metab 26: 230-252.

91. Heo JH, Han SW, Lee SK (2005) Free radicals as triggers of brain edema formation after stroke. Free Radic Biol Med 39: 51-70.

92. Jian Liu K, Rosenberg GA (2005) Matrix metalloproteinases and free radicals in cerebral ischemia. Free Radic Biol Med 39: 71-80.

93. Moskowitz MA, Lo EH, ladecola C (2010) The science of stroke: mechanisms in search of treatments. Neuron 67: 181-198.

94. Kutty RK, Maines MD (1981) Purification and characterization of biliverdin reductase from rat liver. J Biol Chem 256: 3956-3962.

95. Wu J, Hua Y, Keep RF, Nakamura T, Hoff JT, et al. (2003) Iron and ironhandling proteins in the brain after intracerebral hemorrhage. Stroke 34: 2964 2969 .

96. Nakamura T, Keep RF, Hua Y, Schallert T, Hoff JT, et al. (2004) Deferoxamineinduced attenuation of brain edema and neurological deficits in a rat model of intracerebral hemorrhage. J Neurosurg 100: 672-678.

97. Huang FP, Xi G, Keep RF, Hua Y, Nemoianu A, et al. (2002) Brain edema after experimental intracerebral hemorrhage: role of hemoglobin degradation products. J Neurosurg 96: 287-293

98. Nakamura T, Xi G, Park JW, Hua Y, Hoff JT, et al. (2005) Holo-transferrin and thrombin can interact to cause brain damage. Stroke 36: 348-352.

99. Sadrzadeh SM, Anderson DK, Panter SS, Hallaway PE, Eaton JW (1987) Hemoglobin potentiates central nervous system damage. J Clin Invest 79: 662 664.

100.Sadrzadeh SM, Eaton JW (1988) Hemoglobin-mediated oxidant damage to the central nervous system requires endogenous ascorbate. J Clin Invest 82 1510-1515.

101. Juranek I, Bezek S (2005) Controversy of free radical hypothesis: reactive oxygen species--cause or consequence of tissue injury? Gen Physiol Biophys 24: 263-278.

102. Facchinetti F, Dawson VL, Dawson TM (1998) Free radicals as mediators of neuronal injury. Cell Mol Neurobiol 18: 667-682

103. Weiss SJ (1989) Tissue destruction by neutrophils. N Engl J Med 320: 365 376.

104. Gu Z, Kaul M, Yan B, Kridel SJ, Cui J, et al. (2002) S-nitrosylation of matrix metalloproteinases: signaling pathway to neuronal cell death. Science 297: 1186-1190.

105. Huang CY, Fujimura M, Noshita N, Chang YY, Chan PH (2001) SOD1 downregulates NF-kappaB and c-Myc expression in mice after transient focal cerebral ischemia. J Cereb Blood Flow Metab 21: 163-173.

106. Huang CY, Fujimura M, Chang YY, Chan PH (2001) Overexpression of copper-zinc superoxide dismutase attenuates acute activation of activato protein-1 after transient focal cerebral ischemia in mice. Stroke 32: 741-747.

107. Wenk J, Brenneisen P, Wlaschek M, Poswig A, Briviba K, et al. (1999) Stable overexpression of manganese superoxide dismutase in mitochondria identifies hydrogen peroxide as a major oxidant in the AP-1-mediated induction of matrix-degrading metalloprotease-1. J Biol Chem 274: 25869-25876.

108. Gurjar MV, Deleon J, Sharma RV, Bhalla RC (2001) Role of reactive oxygen species in IL-1 beta-stimulated sustained ERK activation and MMP-9 induction. Am J Physiol Heart Circ Physiol 281: H2568-574.

109. Gasche Y, Copin JC, Sugawara T, Fujimura M, Chan PH (2001) Matrix metalloproteinase inhibition prevents oxidative stress-associated blood-brain barrier disruption after transient focal cerebral ischemia. J Cereb Blood Flow Metab 21: 1393-1400

110. Chan PH, Schmidley JW, Fishman RA, Longar SM (1984) Brain injury, edema and vascular permeability changes induced by oxygen-derived free radicals. Neurology 34: 315-320.

111. Kim GW, Lewén A, Copin J, Watson BD, Chan PH (2001) The cytosolic antioxidant, copper/zinc superoxide dismutase, attenuates blood-brain barrier disruption and oxidative cellular injury after photothrombotic cortical ischemia in mice. Neuroscience 105: 1007-1018. 
Citation: Lapchak PA, Wu Q (2011) Vascular Dysfunction in Brain Hemorrhage: Translational Pathways to Developing New Treatments from Old Targets. J Neurol Neurophysiol S1. doi:10.4172/2155-9562.S1-e001

112. Rosenberg GA (2002) Matrix metalloproteinases in neuroinflammation. Glia 39: $279-291$.

113. Sternlicht MD, Werb Z (2001) How matrix metalloproteinases regulate cell behavior. Annu Rev Cell Dev Biol 17: 463-516.

114. Nelson AR, Fingleton B, Rothenberg ML, Matrisian LM (2000) Matrix metalloproteinases: biologic activity and clinical implications. J Clin Oncol 18 1135-1149.

115. Nagase H (1997) Activation mechanisms of matrix metalloproteinases. Biol Chem 378: 151-160.

116. Yong VW, Power C, Forsyth P, Edwards DR (2001) Metalloproteinases in biology and pathology of the nervous system. Nat Rev Neurosci 2: 502-511.

117. Mun-Bryce S, Wilkerson A, Pacheco B, Zhang T, Rai S, et al. (2004) Depressed cortical excitability and elevated matrix metalloproteinases in remote brain regions following intracerebral hemorrhage. Brain Res 1026: 227-234.

118. Abilleira S, Montaner J, Molina CA, Monasterio J, Castillo J, et al. (2003) Matrix metalloproteinase-9 concentration after spontaneous intracerebral hemorrhage. J Neurosurg 99: 65-70.

119. Alvarez-Sabin J, Delgado P, Abilleira S, Molina CA, Arenillas J, et al. (2004) Temporal profile of matrix metalloproteinases and their inhibitors after spontaneous intracerebral hemorrhage: relationship to clinical and radiological outcome. Stroke 35: 1316-1322.

120. Silva Y, Leira R, Tejada J, Lainez JM, Castillo J, et al. (2005) Molecular signatures of vascular injury are associated with early growth of intracerebra hemorrhage. Stroke 36: 86-91.

121. Rosenberg GA (2009) Matrix metalloproteinases and their multiple roles in neurodegenerative diseases. Lancet Neurol 8: 205-216.

122. Rosenberg GA, Cunningham LA, Wallace J, Alexander S, Estrada EY, et al. (2001) Immunohistochemistry of matrix metalloproteinases in reperfusion injury to rat brain: activation of MMP-9 linked to stromelysin-1 and microglia in cell cultures. Brain Res 893: 104-112.

123. Leib SL, Clements JM, Lindberg RL, Heimgartner C, Loeffler JM, et al. (2001) Inhibition of matrix metalloproteinases and tumour necrosis factor alpha converting enzyme as adjuvant therapy in pneumococcal meningitis. Brain 124: $1734-1742$

124. Wu J, Yang S, Xi G, Song S, Fu G, et al. (2008) Microglial activation and brain injury after intracerebral hemorrhage. Acta Neurochir Suppl 105: 59-65.

125.Zhao X, Zhang Y, Strong R, Grotta JC, Aronowski J (2006) 15d-Prostaglandin $\mathrm{J} 2$ activates peroxisome proliferator-activated receptor-gamma, promotes expression of catalase, and reduces inflammation, behavioral dysfunction, and neuronal loss after intracerebral hemorrhage in rats. J Cereb Blood Flow Metab 26: 811-820.

126. McGeehan GM, Becherer JD, Bast RC Jr, Boyer CM, Champion B, et al. (1994) Regulation of tumour necrosis factor-alpha processing by a metalloproteinase inhibitor. Nature 370: 558-561.

127.Zask A (1996) Inhibition of matrix metalloproteinases: structure based design. Curr Pharm Des 2: 624-661.

128. Yamamoto M, Hirayama R, Naruse K, Yoshino K, Shimada A, et al. (1999) Structure-activity relationship of hydroxamate-based inhibitors on membranebound Fas ligand and TNF-alpha processing. Drug Des Discov 16: 119-130.

129. Black RA, Durie FH, Otten-Evans C, Miller R, Slack JL, et al. (1996) Relaxed specificity of matrix metalloproteinases (MMPS) and TIMP insensitivity of tumor necrosis factor-alpha (TNF-alpha) production suggest the major TNFalpha converting enzyme is not an MMP. Biochem Biophys Res Commun 225: 400-405.

130. Cherney RJ, Wang L, Meyer DT, Xue CB, Arner EC, et al. (1999) Macrocyclic hydroxamate inhibitors of matrix metalloproteinases and TNF-alpha production. Bioorg Med Chem Lett 9: 1279-1284.

131.Dayer JM, Beutler B, Cerami A (1985) Cachectin/tumor necrosis factor stimulates collagenase and prostaglandin E2 production by human synovial cells and dermal fibroblasts. J Exp Med 162: 2163-2168.

132. Mun-Bryce S, Rosenberg GA (1998) Matrix metalloproteinases in cerebrovascular disease. J Cereb Blood Flow Metab 18: 1163-1172.

133. Gearing AJ, Beckett P, Christudoulou M, Churchill M, Clements J, et al. (1994) Processing of tumour necrosis factor-alpha precursor by metalloproteinases. Nature 370: 555-557.
134. Corbel M, Lanchou J, Germain N, Malledant Y, Boichot E, et al. (2001) Modulation of airway remodeling-associated mediators by the antifibrotic compound, pirfenidone, and the matrix metalloproteinase inhibitor, batimastat, during acute lung injury in mice. Eur J Pharmacol 426: 113-121.

135. Falk V, Soccal PM, Grünenfelder J, Hoyt G, Walther T, et al. (2002) Regulation of matrix metalloproteinases and effect of MMP-inhibition in heart transplant related reperfusion injury. Eur J Cardiothorac Surg 22: 53-58.

136. Santucci MB, Ciaramella A, Mattei M, Sumerska T, Fraziano M (2003) Batimastat reduces Mycobacterium tuberculosis-induced apoptosis in macrophages. Int Immunopharmacol 3: 1657-1665.

137.Beck G, Bottomley G, Bradshaw D, Brewster M, Broadhurst M, et al. (2002) (E)-2(R)-[1(S)-(Hydroxycarbamoyl)-4-phenyl-3-butenyl]-2'-isobutyl-2'-(meth anesulfonyl)-4-methylvalerohydrazide (Ro 32-7315), a selective and orally active inhibitor of tumor necrosis factor-alpha convertase. J Pharmacol Exp Ther 302: 390-396.

138. Wang X, Feuerstein GZ, Xu L, Wang H, Schumacher WA, et al. (2004) Inhibition of tumor necrosis factor-alpha-converting enzyme by a selective antagonist protects brain from focal ischemic injury in rats. Mol Pharmacol 65 890-896.

139. Araujo DM, Lapchak. Tumor necrosis factor is involved in behavioral deficits infarct progression and hemorrhage following ischemic strokes: a potential therapeutic target. in SFN.

140. Guo D, Zhang XD, Wu HT, Lin B, Sun XC, et al. (2011) Matrix metalloproteinase 9 inhibition reduces early brain injury in cortex after subarachnoid hemorrhage. Acta Neurochir Suppl 110: 81-84.

141. Guo ZD, Sun XC, Zhang ZH (2011) Mechanisms of early brain injury after $\mathrm{SAH}$ : matrix metalloproteinase 9. Acta Neurochir Suppl 110: 63-65.

142. Horstmann S, Kalb P, Koziol J, Gardner H, Wagner S (2003) Profiles of matrix metalloproteinases, their inhibitors, and laminin in stroke patients: influence of different therapies. Stroke 34: 2165-2170.

143. Horstmann S, Su Y, Koziol J, Meyding-Lamadé U, Nagel S, et al. (2006) MMP2 and MMP-9 levels in peripheral blood after subarachnoid hemorrhage. $J$ Neurol Sci 251: 82-86.

144. Todor DR, Lewis I, Bruno G, Chyatte D (1998) Identification of a serum gelatinase associated with the occurrence of cerebral aneurysms as promatrix metalloproteinase-2. Stroke 29: 1580-1583.

145. Fujimura M, Watanabe M, Shimizu H, Tominaga T (2007) Expression of matrix metalloproteinases (MMPs) and tissue inhibitor of metalloproteinase (TIMP) in cerebral cavernous malformations: immunohistochemical analysis of MMP-2, -9 and TIMP-2. Acta Neurochir (Wien) 149: 179-183.

146. Allan SM, Tyrrell PJ, Rothwell NJ (2005) Interleukin-1 and neuronal injury. Nat Rev Immunol 5: 629-640.

147. Rothwell N (2003) Interleukin-1 and neuronal injury: mechanisms, modification, and therapeutic potential. Brain Behav Immun 17: 152-157.

148. Masada T, Hua Y, Xi G, Yang GY, Hoff JT, et al. (2003) Overexpression of interleukin-1 receptor antagonist reduces brain edema induced by intracerebral hemorrhage and thrombin. Acta Neurochir Suppl 86: 463-467.

149. Masada T, Hua Y, Xi G, Yang GY, Hoff JT, et al. (2001) Attenuation of intracerebral hemorrhage and thrombin-induced brain edema by overexpression of interleukin-1 receptor antagonist. J Neurosurg 95: 680-686.

150. Facchinetti F, Dawson VL, Dawson TM (1998) Free radicals as mediators of neuronal injury. Cell Mol Neurobiol 18: 667-682.

151. Floyd RA (1999) Antioxidants, oxidative stress, and degenerative neurological disorders. Proc Soc Exp Biol Med 222: 236-245.

152. Nakashima M, Niwa M, Iwai T, Uematsu T (1999) Involvement of free radicals in cerebral vascular reperfusion injury evaluated in a transient focal cerebral ischemia model of rat. Free Radic Biol Med 26: 722-729.

153. Cherubini A, Ruggiero C, Polidori MC, Mecocci P (2005) Potential markers of oxidative stress in stroke. Free Radic Biol Med 39: 841-852.

154.Lapchak PA, Araujo DM (2003) Development of the Nitrone-Based Spin Trap Agent NXY-059 to Treat Acute Ischemic Stroke. CNS Drug Rev 9: 253-262.

155. Siesjo BK, Katsura K, Zhao Q, Folbergrová J, Pahlmark K, et al. (1995) Mechanisms of secondary brain damage in global and focal ischemia: speculative synthesis. J Neurotrauma 12: 943-956. 
Citation: Lapchak PA, Wu Q (2011) Vascular Dysfunction in Brain Hemorrhage: Translational Pathways to Developing New Treatments from Old Targets. J Neurol Neurophysiol S1. doi:10.4172/2155-9562.S1-e001

156. Siesjo BK, Siesjo P (1996) Mechanisms of secondary brain injury. Eur J Anaesthesiol 13: 247-268.

157. Nakamura T, Kuroda Y, Yamashita S, Zhang X, Miyamoto O, et al. (2008) Edaravone attenuates brain edema and neurologic deficits in a rat model of acute intracerebral hemorrhage. Stroke 39: 463-469.

158.(2003) Effect of a novel free radical scavenger, edaravone (MCl-186), on acute brain infarction. Randomized, placebo-controlled, double-blind study at multicenters. Cerebrovasc Dis 15: 222-9.

159. Yoshifumi T (2007) Benefits of Pre-treatment with edaravone in tPA intravenous therapy for acute cerebral infarction. in XXIIIrd International Symposium on Cerebral Blood Flow.

160.Wang J, Zhuang H, Dore S (2006) Heme oxygenase 2 is neuroprotective against intracerebral hemorrhage. Neurobiol Dis 22: 473-476.

161. Gong Y, Tian H, Xi G, Keep RF, Hoff JT, et al. (2006) Systemic zinc protoporphyrin administration reduces intracerebral hemorrhage-induced brain injury. Acta Neurochir Suppl 96: 232-236.

162. Wagner KR, Hua Y, de Courten-Myers GM, Broderick JP, Nishimura RN, et al. (2000) Tin-mesoporphyrin, a potent heme oxygenase inhibitor, for treatment of intracerebral hemorrhage: in vivo and in vitro studies. Cell Mol Biol (Noisyle-grand) 46: 597-608.

163.Wan S, Hua Y, Keep RF, Hoff JT, Xi G (2006) Deferoxamine reduces CSF free iron levels following intracerebral hemorrhage. Acta Neurochir Suppl 96 199-202.

164. Lekic T, Hartman R, Rojas H, Manaenko A, Chen W, et al. (2010) Protective effect of melatonin upon neuropathology, striatal function, and memory ability after intracerebral hemorrhage in rats. J Neurotrauma 27: 627-637.

165. Ceulemans AG, Zgavc T, Kooijman R, Hachimi-Idrissi S, Sarre S, et al. (2010) The dual role of the neuroinflammatory response after ischemic stroke: modulatory effects of hypothermia. J Neuroinflammation 7: 74

166. Froehler MT, Ovbiagele B (2010) Therapeutic hypothermia for acute ischemic stroke. Expert Rev Cardiovasc Ther 8: 593-603.

167. van der Worp HB, Macleod MR, Kollmar R (2010) Therapeutic hypothermia for acute ischemic stroke: ready to start large randomized trials? J Cereb Blood Flow Metab 30: 1079-1093.

168. Liu L, Yenari MA (2009) Clinical application of therapeutic hypothermia in stroke. Neurol Res 31: 331-335.

169. Lyden PD, et al. (2006) Therapeutic hypothermia for acute stroke. Int J Stroke 1: 9-19.

170. Kollmar R, Blank T, Han JL, Georgiadis D, Schwab S (2007) Different degrees of hypothermia after experimental stroke: short- and long-term outcome. Stroke 38: 1585-1589.

171. Yenari M, Kitagava K, Lyden P, Perez-Pinzon M (2008) Metabolic downregulation: a key to successful neuroprotection? Stroke 39: 2910-2917.

172. Lee SM, Zhao H, Maier CM, Steinberg GK (2009) The protective effect of early hypothermia on PTEN phosphorylation correlates with free radical inhibition in rat stroke. J Cereb Blood Flow Metab 29: 1589-1600.

173. Liu L, Kim JY, Koike MA, Yoon YJ, Tang XN, et al. (2008) FasL shedding is reduced by hypothermia in experimental stroke. J Neurochem 106: 541-550.

174. MacLellan CL, Davies LM, Fingas MS, Colbourne F (2006) The influence of hypothermia on outcome after intracerebral hemorrhage in rats. Stroke 37: 1266-1270.

175. Kawanishi M, Kawai N, Nakamura T, Luo C, Tamiya T, et al. (2008) Effect of delayed mild brain hypothermia on edema formation after intracerebra hemorrhage in rats. J Stroke Cerebrovasc Dis 17: 187-195.

176. Groysman LI, Emanuel BA, Kim-Tenser MA, Sung GY, Mack WJ (2011) Therapeutic hypothermia in acute ischemic stroke. Neurosurg Focus 30: E17.

177. Hemmen TM, Raman R, Guluma KZ, Meyer BC, Gomes JA, et al. (2010) Intravenous thrombolysis plus hypothermia for acute treatment of ischemic stroke (ICTuS-L): final results. Stroke 41: 2265-2270.

178. Sun L, Zhou W, Mueller C, Sommer C, Heiland S, et al. (2010) Oxygen therapy reduces secondary hemorrhage after thrombolysis in thromboembolic cerebral ischemia. J Cereb Blood Flow Metab 30: 1651-1660.

179. Qin Z, Xi G, Keep RF, Silbergleit R, He Y, et al. (2008) Hyperbaric oxygen for experimental intracerebral hemorrhage. Acta Neurochir Suppl 105: 113-117.

180. Qin Z, Hua Y, Liu W, Silbergleit R, He Y, et al. (2008) Hyperbaric oxygen preconditioning activates ribosomal protein $\mathrm{S} 6$ kinases and reduces brain swelling after intracerebral hemorrhage. Acta Neurochir Suppl 102: 317-320.

181. Ostrowski RP, Colohan AR, Zhang JH (2006) Neuroprotective effect of hyperbaric oxygen in a rat model of subarachnoid hemorrhage. Acta Neurochir Suppl 96: 188-193.

182. Ostrowski RP, Tang J, Zhang JH (2006) Hyperbaric oxygen suppresses NADPH oxidase in a rat subarachnoid hemorrhage model. Stroke 37: 1314 1318

183. Matchett GA, Martin RD Zhang JH (2009) Hyperbaric oxygen therapy and cerebral ischemia: neuroprotective mechanisms. Neurol Res 31: 114-121.

184. Huang ZX, Kang ZM, Gu GJ, Peng GN, Yun L, et al. (2007) Therapeutic effects of hyperbaric oxygen in a rat model of endothelin-1-induced focal cerebral ischemia. Brain Res 1153: 204-213.

185. Fujiwara N, Mandeville ET, Geng X, Luo Y, Arai K, et al. (2011) Effect of normobaric oxygen therapy in a rat model of intracerebral hemorrhage. Stroke 42: $1469-1472$

186. Fujiwara N, Murata Y, Arai K, Egi Y, Lu J, et al. (2009) Combination therapy with normobaric oxygen (NBO) plus thrombolysis in experimental ischemic stroke. BMC Neurosci 10: 79.

187. Singhal AB, Benner T, Roccatagliata L, Koroshetz WJ, Schaefer PW, et al. (2005) A pilot study of normobaric oxygen therapy in acute ischemic stroke. Stroke 36: 797-802

188. Lapchak PA, Zhang JH (2011) Resolving the Negative Data Publication Dilemma in Translational Stroke Research. Translational Stroke Research 2 : 1-6.

189. Chen CH, Manaenko A, Zhan Y, Liu WW, Ostrowki RP, et al. (2010) Hydrogen gas reduced acute hyperglycemia-enhanced hemorrhagic transformation in a focal ischemia rat model. Neuroscience 169: 402-414.

190.Zhang QL, Du JB, Tang CS (2011) [Hydrogen and oxidative stress injury--from an inert gas to a medical gas]. Beijing Da Xue Xue Bao 43: 315-319.

191.Dirnagl U, ladecola C, Moskowitz MA (1999) Pathobiology of ischaemic stroke: an integrated view. Trends Neurosci 22: 391-397.

192.Zhao BQ, Tejima E, and Lo EH (2007) Neurovascular proteases in brain injury, hemorrhage and remodeling after stroke. Stroke 38: 748-752.

193.Lapchak PA (2011) Emerging Therapies: Pleiotropic Multi-target Drugs to Treat Stroke Victims. Translational Stroke Research 2: 129-135.

194. White BC, Sullivan JM, DeGracia DJ, O’Neil BJ, Neumar RW, et al. (2000) Brain ischemia and reperfusion: molecular mechanisms of neuronal injury. $J$ Neurol Sci 179: 1-33.

195. Lapchak PA (2010) A critical assessment of edaravone acute ischemic stroke efficacy trials: is edaravone an effective neuroprotective therapy? Expert Opinion on Pharmacotherapy 11: 1753-1763

196. Lapchak PA (2011) Neuroprotective and neurotrophic curcuminoids to trea stroke: a translational perspective. Expert Opin Investig Drugs 20: 13-22.

197. Ginsberg MD (2008) Neuroprotection for ischemic stroke: past, present and future. Neuropharmacology 55: 363-389.

198. Fisher M (2011) New approaches to neuroprotective drug development Stroke 42: 24-27.

199. Woodruff TM, Thundyil J, Tang SC, Sobey CG, Taylor SM, et al. (2011) Pathophysiology, treatment, and animal and cellular models of human ischemic stroke. Mol Neurodegener 6: 11

200. Tuttolomondo A, Di Sciacca R, Di Raimondo D, Arnao V, Renda C, et al. (2009) Neuron protection as a therapeutic target in acute ischemic stroke. Curr Top Med Chem 9: 1317-1334. 